killed by 0.3 gram weight in less than twenty-four hours and 0.5 c.c. kills sound white rats of 150 grams weight in thirty to fifty minutes. It seems to be identical with the TO of $R$. Koch. After this result I can not think that by any method more soluble substance can be extracted from the tuberculin bacilli by a fluid containing 5 per cent. glycerin. The high toxic effect of this substance is defending the use for healing purposes, which view Koch seems also to accept by going over to the production of TR. All these extracted substances are contained in the tuberculocidin (TC), eliminating the toxins by precipitation with sodium bismuth iodid. The often repeated effect of this substance is that the higher temperature of tuberculous animals and man is suppressed and the tubercle bacilli are killed, the tuberculous tissue reabsorbed without formation of scars where the tissues are not wholly necrotized. That also the gravest infection of guinea-pigs can heal I have shown last year. (Journal of the American Medical AssociaTION, l. c.) It seems to me to be of the highest value to compare the immunizing property of the tubercle bacilli extract made without crushing the T.B. and after crushing them as is made in the preparation of TR. In experiments on guinea-pigs, begun immediately after having received the publication of Koch (in April) on T. B. killed with kresol, 0.2 per cent., I have found no difference in the immunizing power of the extracts made by my method and by the method of Koch. The first seemed to be more efficient, but this may depend on a somewhat higher concentration. So I am sure that the precipitation with $\mathrm{NaBiI}_{3}$ does not destroy the immunizing substance contained in the T. B. As to the question, whether living T. B. give more of this substance, it seems to me very questionable, for if this substance would be destroyed by the death of $T$. B. our preparations must have become totally ineffectual.

The difficulties in preparing $T R$ from living T. B. lie, as I have shown, in the danger of the presence of some living T. B. in the fluid as long as the fluid is opalescent, by the presence of gelatinous matter. Within the last few days I have found a method of eliminating these certainly superfluous or dangerous admixtures, using the usual centrifuge, giving no more than 2,680 rotations per minute. By adding finely powdered carbonate of magnesia the fluid can be cleared up by a rotation of 2,000 per minute. All this gelatinous matter and with it some T. B. escaping the crushing is precipitated and included in the magnesia deposit. The experiments with these fluids will be begun now and will be referred to in due time. Addition of conservative fluids, as 0.2 per cent. orthocresol, will be tried in these experiments. The danger of contamination at the time of the preparation must be avoided, as far as possible, by always using fluids immediately after having centrifuged them with magnesia.carbonate. For human use such preparations must be avoided, but the theoretic question seems to be interesting.

Wire Springs to Hold open Operated Abscesses.-E. Braatz uses a small wire spring shaped something like a fancy $W$, or a spiral for deep abscesses, to keep the openings from closing after evacution of the pus, thus facilitating free discharge. $\mathrm{He}$ has them made in various sizes, and if necessary, combines a rubber drain with them, which he always slits lengthwise, to secure better drainage. This is a return to the old spirals of Chaissaignac.-Cbl.f. Chir., April 24.

\section{GENERAL MEDICINE A SPECIALTY IN ITSELF; ITS RELATION TO THE RECOGNIZED SPECIALTIES, PARTICULARLY TO BACTERIOLOGY.}

Read in the Section on Practice of Medicine, at the Forty-eighth Annual Meeting of the American Medical Association, at Philadelphia, Pa., June 1-4,1897.

BY GEORGE BYRD HARRISON, M.D.

President of the Obstetrical, Gynecological and Pediatric Society; Professor of Diseases of Children, Columbian University: Senior Phy
siciau Washington City Orphan Asylum; Member of Attending Staff, Department of General Diseases Central Dispensary and Emergency Hospital, ete.

$$
\text { WASHINGTON, D. C. }
$$

I wish to urge upon you, as forcibly as I can, that the time has come when we should claim with all our energy that the department of medicine in which we are engaged (the noblest of all the divisions of the science, because the most comprehensive, and calling into play the intellectual faculties as none other can possibly do), is, and of right should be, a specialty in itself, claiming not only recognition from the "mani. pulative" (or otherwise limited), recognized specialties, but occupying toward them the position of a parent to children - a fostering care which they can not do without, unless they are content to be relegated to the domain of sciolism and quackery. These are strong expressions, but not too emphatic for the occasion. A brilliant medical man, of admirable attainment in the theory of medicine, of thorough hospital training and very considerable experience in private practice, told me (within a fow weeks), that he had made up his mind to quit private practice and enter the Marine-Hospital Service. Having been out of the class-room so long, and with little time to prepare for examination, he had some misgivings as to his ability to compete with men fresh from their textbooks. But, he added, I have come to this deliberate conclusion, that the time is not far distant when none but the rich can afford to indulge in the practice of general medicine. He carried out his plan, and out of three places competed for by thirty odd applicants, took the first position and is now installed in that service. This illustration of what is likely to occur very generally, has struck me forcibly. If the present system goes on we will all be impelled to quasi specialism-which is as dishonest as modern homeopathy - or else to give up civil practice altogether.

Let us contemplate the picture as it is presented day by day. We call a laryngologist to a case, because under the Hippocratic oath we feel obliged to give the patient the advantage of manipulative skill and constant practice Everything goes well with this individual, and we congratulate ourselves upon our consideration for the patient and his friends. Very soon we hear of another case in the same household, construed by the friends to be a suitable one for a specialist, and the specialist whom we have introduced is installed. Perhaps there may have been a shade of difference in the conditions, and with our superior knowledge of the qualifications of the various men engaged in this line, we might have preferred some one else to meet the phenomena which long acquaintance with the patient and his relations makes us more fit to interpret than any one else; but the man whom we introduced into the household takes not only precedence, but absolute control of the situation; we have not even an opportunity for remonstrance, much less of interference. 
Again, one of our constituents, of advanced years, though in admirable health and gaining weight, goes to an aurist to have the cerumen (if there be an accumulation), removed from his ears. The specialist goes through the routine of ear syringing, and prescribes arsenic. The general practitioner is soon called to relieve the patient of violent herpes zoster induced by arsenic-for the patient is intolerant of all drugs, as his general physician well knows.

In another instance a gentleman of rheumatic diathesis has a limp on his forehead, which his physician is treating with iodin ointment and making light of, because the patient is syphilophobic and the physician has sifted the evidence and eliminated such a possibility. The doctor, unwilling to rob him by a consultation (there being no need for one), sends him to a specialist, with a note detailing treatment and asking if any should be added. $\mathrm{He}$ sees no more of his patient for months, and when he reports, is told that the surgeon diagnosed syphilis and prescribed iodid of potassium.

A distinguished gynecologist and obstetrician will attend a male hotel guest seized with cholera morbus, when general physicians are within easy call. The same gentleman will consult in a fatal case of septic dysentery, and perhaps next day perform abdominal section.

An eye case will be placed under the charge of a careless (or at least not well-selected) specialist, by the patient's irriends, and loss of sight be the actual and logical result.

An aged person suffering from cophosis will be sent by some kind patron to an aurist, and encouraged by him to pay regular visits for a protracted period, when the general attendant, knowing the history of the case, could have predicted the result (negative except to the aurist), and have saved the patron needless and wasteful expenditure.

These illustrations could be multiplied almost indefinitely, but enough have been given to "point the moral." "My brethren, these things ought not so to be." We have a duty to the general public, a duty to ourselves, and an obligation also to the true and regular specialists, of whom we all know a few. 'These cases which I have cited are not fancy sketches, but (mutatis mutandis) living pictures actually observed day by day. They are not complimentary to our great profession; but they are facts, stubborn and hard to correct, but which we are bound to face and endeavor to correct; and moreover, they can be corrected, if we are true to ourselves and to the much. vaunted ethics of our Code. Indeed, it is through the Code of Ethics of the American Medical AssociaTION that they must be fought. There may be difference of opinion, and profitable discussion, as to the manner of correction, but our duty is paramount, if the prestige of regular medicine is to be preserved. I venture two suggestions:

1. Instead of prohibiting the specialist from so proclaiming himself, on his sign (as is now the rule of his special association), he should be made to do so Then we could mark his errors, and deal with them ethically.

2. Our Code might be amended, so that a patient, presenting himself in a physician's office for the first time, should be asked who his regular attendant was, and after receiving treatment, should be referred to his attendant, in order that the treatment given might be approved and supplemented, or condemned; for, as we have said before, by reason of superior knowledge concerning the individual's constitution, antecedents and environment, he is the best qualified judge of the situation. It is manifest that one division of our science should not be bound by the law of Hippocrates, if the rest are to be free lances-ce va sans dire.

But let us now consider certain aspects of the relations of general medicine and bacteriology, as it presents itself up to date - a science of inestimable value today, and of incalculable potentialities in the future. It is, however, greatly to be feared lest in some of its careless and unintelligent applications, it do more harn than good. In no direction is its inexact employment more disastrous, according to our observation, than in the diagnosis of diphtheria.

Through its instrumentality, the National Capital, at the very opening of the present Congressional year, was accredited with an "epidemic of diphtheria." From our own experience and practice, which is largely amongst children (though we repudiate any claim to reputation as a specialist in this line), the writer deliberately asserts that, for seventeen years, he believes the community has not been so free from diphtheria. This observation coincides with opinions expressed to him by many of the leading members of the profession here. The writer, besides his private practice, is and has for fifteen years been the senior physician of one of the largest orphan asylums of the city, whose children have entrée to the public schools, and whose inmates friends visit them weekly. Within two years and a half, we have seen one case of diphtheria, and no case of fatal sore throat nor fatal laryngitis in our whole practice; and yet this has been heralded to the world as a plague spot. We have seen angina membranacea, follicular tonsillitis, herpetic sore throat, aphthous sore throat, etc., but these have all yielded promptly to antiseptic and aseptic measures with isolation and ventilation, coupled with appropriate general and local treatment, including stimulation and proper diet. We believe the disease has in no case been transferred from one member of the family to another. In all, there has been spontaneous tendency to recovery and actual recovery.

1223 Connecticut A venue.

\section{ON TRACHEAL TUGGING IN CONDITIONS OTHER THAN ANEURYSM OF THE TRANSVERSE PORTION OF THE} ARCH OF THE AORTA.

Read in the Section on Practice of Medicine, at the Forty eighth Annual Meeting of the American Medical Association, beld

BY HARRY TOULMIN, M.D.

INSTRUCTOR IN PHYSICAL DIAGNOSIS, UNIVERSTTY OF PENNSYLYANIA. PIILLADELPHA.

While serving as medical interne at the Johns Hopkins Hospital under Dr. Osler, some years ago, I became impressed by the frequency with which cases of aneurysm of the transverse portion of the arch of the aorta were accompanied by tracheal tugging. Desiring to know if this phenomenon might occur in other diseases or in health, I recently began to collect statistics, and desire to make today what, on account of the small number thus far examined, can only be called a preliminary report.

I found that results of work on similar lines bad been published by Grimsdale ${ }^{1}$ and by Ewart, ${ }^{2}$ and a

1 Practitioner, February, 1892.

¿ British Medical Journal, March 19, 1892. 